\title{
Betamethasone valerate compared with sodium cromoglycate in asthmatic children
}

\author{
S. H. NG \\ M.B., B.S., M.R.C.P., D.C.H. \\ C. H. DASH* \\ M.B., Ch.B., D.Obst.R.C.O.G. \\ Suzanne J. Savage \\ M.B., B.S., D.Obst.R.C.O.G. \\ Children's Hospital, Sydenham, London SE26, and *Medical Department, Glaxo Laboratories Ltd, \\ Greenford, Middlesex
}

\begin{abstract}
Summary
A double-blind, cross-over study was undertaken to compare inhalations of betamethasone valerate $(\mathrm{BV}$, $800 \mu \mathrm{g}$ daily) with sodium cromoglycate (SCG, $80 \mathrm{mg}$ daily) in twenty children requiring bronchodilators for perennial asthma. Each treatment period lasted 4 weeks but statistical comparisons were made only in respect of the last 14 days of each therapy. When the children were using BV they required not only less of the bronchodilator drugs but had fewer symptoms and higher daily peak expiratory flow rates when taking SCG. Statistically, all these differences were highly significant. For 2 weeks before the main trial each child was given a placebo aerosol (single-blind) to assess severity of asthma. In comparison with this period, SCG was associated with a significantly increased peak expiratory flow rate a lower symptom score by day but not by night, but their usage of bronchodilators followed a similar pattern. When the BV period was compared with the placebo period, patients had an even more significant rise in peak expiratory flow rate, less day and night symptoms, and took hardly any bronchodilators. The response to the two drugs did not seem to depend upon which was given first. No monilial infections were found, nor any measurable defect in adrenal response from either treatment. Betamethasone valerate is considered to be superior to sodium cromoglycate as a treatment for childhood asthma insufficiently controlled on bronchodilators.
\end{abstract}

\section{Introduction}

There is no doubt that sodium cromoglycate (SCG) is of value in the management of childhood asthma (Chai et al., 1970; Smith and Devey, 1968). Silverman et al. (1972) showed that $71 \%$ of their patients not taking steroids were effectively controlled by SCG. Godfrey, Balfour-Lynn and König (1975) found that about $25 \%$ of their asthmatic children still required steroids in spite of being on

Correspondence: Dr S. H. Ng, Consultant Paediatrician, Farnborough Hospital, Locksbottom, Kent.
SCG. Long-term corticosteroids have unfortunately a constellation of unwanted side effects in the growing child, and the advent of inhaled metered aerosol preparations of corticosteroids having a high topical action relative to their systemic effect, such as beclomethasone dipropionate and betamethasone valerate, have been shown to be beneficial in the control of childhood asthma (Dickson et al., 1973; Frears, Wilson and Friedman, 1973; Howard and Jacoby, 1974). Bethamethasone valerate was noted by Kuzemko et al. (1974) to be more effective than sodium cromoglycate when both were given twice daily. Hiller and Milner (1975) reported that patients who were not well controlled on sodium cromoglycate gained no greater benefit from the addition of betamethasone valerate than was gained by giving the steroid alone.

The clinical response of asthmatic children under controlled conditions has been studied in a trial designed as a double-blind, cross-over study to compare betamethasone valerate (BV) with sodium cromoglycate (SCG) by inhalation in the treatment of children whose asthma was not controlled satisfactorily on bronchodilator therapy and who were, therefore, under consideration for more intensive treatment with SCG or corticosteroids.

\section{Methods}

With informed parental consent, twenty children took part in the trial which was double-blind. They were selected on the basis that their asthma was inadequately controlled on regular bronchodilator therapy. All the children had reversible mucosal or airways obstruction and evidence of atopy. The mean age was 9.7 years (range $6 \cdot 7-13.7$ years), the mean height was $133 \mathrm{~cm}$ (range $114-153 \mathrm{~cm}$ ), and mean weight was $28.1 \mathrm{~kg}$ (range $20.0-37.5 \mathrm{~kg}$ ). The mean peak expiratory flow rate (PEFR) was $52 \%$ of the predicted normal value (Polgar and Promadhat, 1971). All the children had been off school for significant periods, averaging two spells per month, because of asthma. None was in remission but they 
were all able to use the inhalers, the Wright Peak Flow Meter, and to complete a diary card modified from that described by Connolly and Godfrey (1970). No regular systemic corticosteroids had been given to any of the children in the 3 months preceding the trial.

The steroid aerosol delivered $100 \mu \mathrm{g} \mathrm{BV}$ in each metered dose; its corresponding placebo contained propellants only but appeared identical to its active counterpart. The capsules contained $20 \mathrm{mg}$ SCG or inert placebo and appeared identical. The first 2 weeks of the trial were devoted to an objective assessment of the severity of asthma. During this period the children inhaled two puffs, four times daily, from an aerosol which the physician alone knew to be a placebo. After this initial period the patients were randomly assigned to $\mathrm{BV}$ plus placebo Spincap, or placebo BV plus SCG. Although the patients knew that at the end of 4 weeks the alternative therapy was to be given for a further 4 weeks, they were unable to identify any physical differences between them. Each treatment regimen consisted of inhalation of two puffs of the metered aerosol and the contents of one capsule four times daily at fixed times thus allowing comparison of the response to $200 \mu \mathrm{g}$ q.i.d. of BV and $20 \mathrm{mg}$ q.i.d. of SCG to be made.

Throughout the 10 weeks of the trial the children were asked to use their bronchodilators on demand. Every morning, each child recorded the symptom score for the night (0-3) and the greatest of three PEFRs, before any bronchodilator therapy. In the evening, the scores of the symptoms during the day (0-8) and a repeat PEFR were recorded. The greater the symptom score, the worse the symptoms. The number of doses of their usual bronchodilator in each $24 \mathrm{hr}$, as well as the taking of any additional drugs, were also recorded.

Once every fortnight each child attended the outpatient clinic where the clinical progress and any side effects were assessed. A short tetracosactrin test (Wood et al., 1965) was performed after the initial placebo period and after the two 4-week periods of active therapy. A normal response was defined as a plasma cortisol level greater than $18 \mu \mathrm{g} / 100 \mathrm{ml} 30$ min after the tetracosactrin injection.

At the end of the trial each child, in consultation with a parent, was asked which treatment period was preferred. The clinician assessed objectively the better month for the child. The code was then broken and the child was provided in an open way with the more beneficial treatment for a further 6month period.

As neither of the two treatments was expected to give an immediate response and to avoid any "carryover' effects from the first treatment to the second, only the data collected during the last 14 days of each period were analysed. This decision was taken at the start of the trial. The paired $t$-test was used to analyse the PEFR, and the Wilcoxon matched-pairs signed-ranks test was applied to the symptom scores and bronchodilator usages. The levels of significance for a two-tailed test are given.

In addition to comparing BV and SCG, the effects of the two drugs were separately compared with the initial placebo period, using the same statistical tests. However, because of the accepted benefit of both drugs over placebo, reference to single-tailed tests was made to obtain the levels of significance. Finally, the randomization allowed patients to be divided into two sub-groups: one given BV first (A) and the other given SCG first (B). Hence it is possible to study whether the order of administration affected the responses. Sub-groups A and B were compared statistically in respect of their PEFRs, initial ages, heights and weights, using Student's $t$-test for independent samples. Symptom scores and bronchodilator usages were compared by the Mann-Whitney $U$-test. When comparing the responses of the same patients in each sub-group separately, the Wilcoxon matched-pairs signed-ranks test was used. Levels of significance were derived as for two-tailed tests.

\section{Results}

All twenty children satisfactory completed the 10 weeks of the trial. Before decoding the respective treatments, nineteen of the patients chose, without hesitation, the BV therapy as the better period. One preferred SCG although analysis showed that BV had produced significantly greater improvement for this patient in all objective indices.

The group mean values for each 2-week period are given in Table 1, together with the results of the statistical comparisons.

\section{Bronchodilator usage}

Salbutamol tablets $(2 \mathrm{mg}$ ) were the usual bronchodilators for eighteen of the patients. One used these in combination with aminophylline suppositories, and the remaining child used $5 \mathrm{mg}$ terbutaline tablets.

Four patients did not take bronchodilators during either the SCG or BV periods. Sixteen patients needed bronchodilators with SCG, fourteen of them taking more in this period than with BV. Only three patients took bronchodilators at all during the BV period. On average, each patient required 0.65 doses of bronchodilators per day with SCG and 0.03 doses/ day with BV and this reduction was statistically significant $(P<0 \cdot 01$, Table 1).

In comparison with the initial placebo period, all patients used less bronchodilators with BV. By contrast, four used the same amount on SCG, twelve used less, but four used more than in the placebo 
TABLE 1. Analyses of objective and subjective indices, measured daily by all twenty patients (mean values)

\begin{tabular}{lcccccrc}
\hline & \multicolumn{3}{c}{ Treatment period } & & \multicolumn{2}{c}{ Significance of difference $(P)$} \\
\cline { 2 - 4 } Indices & Placebo & SCG & BV & & BV v. SCG & BV v. Placebo SCG $v$. Placebo \\
\hline Bronchodilator use (dose/day) & 0.85 & 0.65 & 0.03 & & $<0.01$ & $<0.005$ & n.s. \\
Night symptom score* & 0.78 & 0.54 & 0.06 & $<0.01$ & $<0.005$ & $<0.025$ \\
Day symptom score* & 2.6 & 1.7 & 0.3 & $<0.01$ & $<0.005$ & $<0.005$ \\
Total symptom score* & 3.3 & 2.3 & 0.3 & $<0.01$ & $<0.005$ & $<0.005$ \\
Morning PEFR (1/min) & 150 & 172 & 235 & $<0.001$ & $<0.0005$ & $<0.01$ \\
Evening PEFR (1/min) & 159 & 187 & 249 & $<0.001$ & $<0.0005$ & $<0.01$ \\
\hline
\end{tabular}

* Lower scores represent less severe asthma; $\mathbf{B V}=$ betamethasone valerate; $\mathbf{S C G}=$ sodium cromoglycate; n.s. $==$ not significant.

period. The mean number of doses daily during placebo was $0 \cdot 85$, which did not differ statistically from the SCG period but was significantly greater than with BV $(P<0.005)$.

\section{Symptom scores}

Fourteen children had no symptom at night during BV, but only one was asymptomatic with SCG. The mean night scores were 0.06 and 0.54 respectively: $\mathrm{BV}$ was significantly more effective than SCG in preventing asthma at night $(P<0.01)$. During the initial placebo period only one patient had had no symptom at night and the mean score for the group was 0.78 which was significantly less than with either active therapy (Table 1).

Both drugs reduced the total symptom score significantly for the $24 \mathrm{hr}(P<0.005)$, BV being more effective than SCG $(P<0.01$, Table 1$)$.

\section{Peak expiratory flow rates}

Morning PEFR. For eighteen patients the morning PEFRs were greater during BV than SCG therapy and in seventeen of them the differences were highly significant $(P<0.005)$. During $\mathrm{BV}$, there was a significant and clinically useful increase of $631 / \mathrm{min}$ (to $2351 / \mathrm{min})$ over that during SCG $(P<0.001)$. Compared with placebo, all the morning PEFRs during $\mathrm{BV}$ were greater and eighteen of them are statistically significant $(P<0.005)$. When the SCG period was compared with the placebo the drug was found to be associated with a significantly greater morning PEFR in eight patients, but with a significantly lower PEFR in one. The other eleven patients had no significant change although four of these recorded lower PEFRs. SCG treatment was associated with a significant increase of $221 / \mathrm{min}$ over placebo $(P<0.01$, Table 1).

Evening PEFR. The mean evening PEFRs were slightly greater than the corresponding morning values (Table 1). When the two treatments were compared, eighteen patients had greater evening PEFRs during BV than during SCG and of these, seventeen were highly significant. Two patients had slightly lower PEFRs during BV but these differences were not significant. For the whole group, the difference between BV and SCG was highly significant $(P<0.001)$.

When the average evening PEFR of each patient during SCG was calculated it was found in ten patients to be significantly greater than during placebo, lower in two patients and not significantly different in eight. By comparison, the PEFRs of eighteen patients when on BV showed significant increases over the placebo values, and none was lower. Both drugs produced significantly greater evening PEFRs than did placebo (Table 1).

\section{Short tetracosactrin tests}

All twenty children underwent this test on each of the three specified occasions. During the initial placebo period, eighteen patients had normal responses and two had sub-normal responses. One of these two had a slightly increased but still subnormal response after 28 days of BV treatment, which followed immediately after the placebo. This improvement probably indicated continuing return of normal adrenocortical response. The other, together with the remaining eighteen patients, had normal blood cortisol responses after tetracosactrin at the end of 28 days BV treatment. All the patients disliked the tetracosactrin injections which were undoubtedly painful.

\section{Adverse effects}

Side effects were sought throughout the trial. Candida albicans was cultured from one patient at the beginning but cleared spontaneously during the active treatment periods. No oral or nasal thrush was observed in the BV or SCG period.

\section{Comparison of sub-groups $A$ and $B$}

The twenty patients, after decoding, were divided into two sub-groups of ten. Sub-group A, after the initial 14 days on placebo, had BV for 28 days followed by SCG for 28 days. Sub-group B, after the initial placebo period, had SCG followed by BV.

The mean symptom scores, PEFRs and bronchodilator usage for each day of the trial according to 

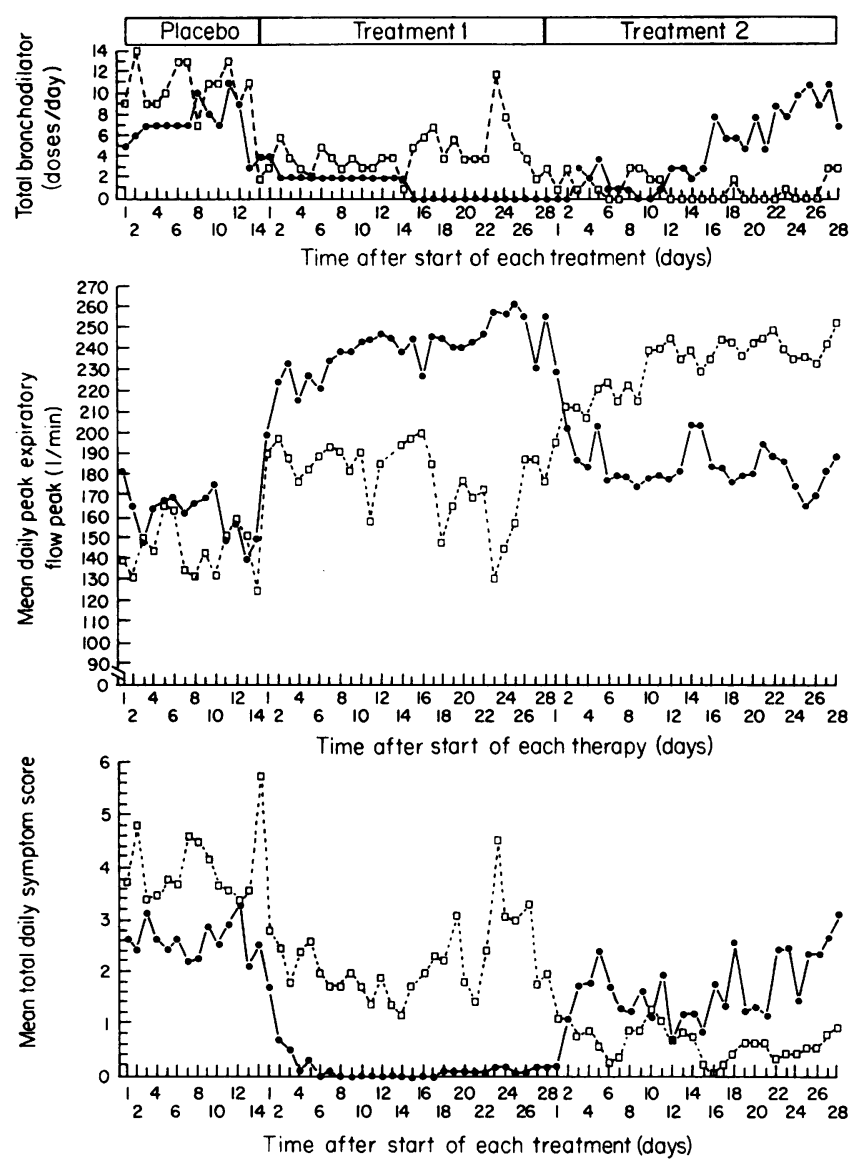

Fig. 1. Mean daily progress of patients as assessed by number of doses of bronchodilators, symptom scores and daily PEFR, according to whether the first drug they received was BV (O-O) or SCG ( $\square---\square)$.

TABLE 2. Mean daily values of objective and subjective indices measured by each sub-group of ten patients

\begin{tabular}{|c|c|c|c|c|c|c|c|}
\hline \multirow{2}{*}{$\begin{array}{l}\text { Sub- } \\
\text { group }\end{array}$} & \multirow[b]{2}{*}{ Indices } & \multicolumn{3}{|c|}{ Treatment period } & \multicolumn{3}{|c|}{ Significance of difference $(P)$} \\
\hline & & Placebo & SCG & BV & BV v. SCG & BV v. Placebo & SCG $v$. Placebo \\
\hline A & $\begin{array}{l}\text { Bronchodilator use (dose/day) } \\
\text { Total symptom scores* } \\
\text { Mean daily PEFR (1/min) }\end{array}$ & $\begin{array}{r}0 \cdot 7 \\
2 \cdot 6 \\
164\end{array}$ & $\begin{array}{l}0 \cdot 76 \\
2 \cdot 0 \\
182\end{array}$ & $\begin{array}{l}0 \\
0 \cdot 1 \\
246\end{array}$ & $\begin{array}{l}<0.05 \\
<0.01 \\
<0.005\end{array}$ & $\begin{array}{l}<0.025 \\
<0.005 \\
<0.0005\end{array}$ & $\begin{array}{l}\text { n.s. } \\
\text { n.s. } \\
\text { n.s. }\end{array}$ \\
\hline B & $\begin{array}{l}\text { Bronchodilator use (dose/day) } \\
\text { Total symptom scores* } \\
\text { Mean daily PEFR ( } 1 / \mathrm{min})\end{array}$ & $\begin{array}{r}1 \cdot 0 \\
4 \cdot 0 \\
146\end{array}$ & $\begin{array}{r}0 \cdot 5 \\
2 \cdot 5 \\
179\end{array}$ & $\begin{array}{l}0.06 \\
0.5 \\
240\end{array}$ & $\begin{array}{l}<0.02 \\
<0.01 \\
<0.005\end{array}$ & $\begin{array}{l}<0.01 \\
<0.005 \\
<0.005\end{array}$ & $\begin{array}{l}<0.025 \\
<0.005 \\
<0.025\end{array}$ \\
\hline
\end{tabular}

* Lower score represents lower severity; $\mathrm{BV}=$ betamethasone valerate; $\mathrm{SCG}=$ sodium cromoglycate; n.s. = not significant.

sub-group are shown in Fig. 1. Although inspection suggests some difference between the sub-groups during the initial placebo period, analyses of the three factors as well as of ages, heights and weights did not reveal any statistical differences. It seemed reasonable therefore to compare the behaviour of the two sub-groups. The mean values for the various objective variables, and the results of statistical comparisons, are given for sub-group $\mathrm{A}$ and sub-group B in Table 2. In sub-group A, SCG when compared with placebo seemed to have no significant effect on symptoms, bronchodilator usage or mean daily 
PEFR. BV reduced total symptoms significantly for sub-group A compared with sub-group $B(P<0.05)$. Otherwise, there were no differences between the behaviour of these two sub-groups. The differences in mean daily PEFR between the two treatments were $64 \mathrm{l} / \mathrm{min}$ in sub-group $A$ and $61 \mathrm{l} / \mathrm{min}$ in subgroup $B$.

Sub-group A, after the initial placebo period, was put on BV. The mean daily PEFR rose rapidly during the first 14-day period of BV and the elevation was sustained in the second 14-day period. The mean daily PEFR fell rapidly when the treatment was changed to SCG and the lower level was then maintained throughout both 14-day periods.

Sub-group B, after the initial placebo period, was put on SCG. There was a less marked elevation of the mean daily PEFR during the first 14-day period of SCG but this elevation was not sustained in the second 14-day period. When the patients were put on $\mathrm{BV}$, there was a rapid elevation of the mean daily PEFR and during the second 14-day period, the plateau appeared to have been reached.

There was no difference between the mean daily PEFR of each sub-group during BV therapy whether one considers the first fourteen day period, the second, or the whole 28 days. Similarly there were no differences between the two sub-groups when treated with SCG.

\section{Discussion and conclusions}

Sodium cromoglycate appeared to be more effective during the waking hours when the patient was having his inhalation, but its effect did not persist through the sleeping hours. Betamethasone valerate, on the other hand, appeared to be effective in reducing asthma throughout the whole $24 \mathrm{hr}$. The comments made by parents, that the children played more strenuous games during BV confirmed that exercise-induced bronchoconstriction disappeared after prolonged therapy (Hodgson, McPherson and Friedman, 1974) but not after single doses (Hills, Davies and Geary, 1974) and suggest that the effect of BV is either more pronounced or more sustained that that of SCG. Certainly mean PEFRs were greater with BV therapy.

Response to BV was generally detectable by twice daily PEFR measurements within $24 \mathrm{hr}$ and continued to increase over at least the ensuing few days. The effects of SCG seemed to follow a similar timecourse. The rate of response appeared to be slower when BV followed SCG. After stopping BV, the rate of deterioration mirrored that of the initial improvement.

On considering the three indices (symptom scores, bronchodilator usage and PEFR) in an integrated form, it was found that the twenty patients, while on placebo, had low PEFRs and needed broncho- dilators to control their asthma because they had wheezing during the night and day. When they were on SCG, they had slightly improved symptom scores both night and day in comparison with placebo but their bronchodilator usage was not significantly reduced. However, their PEFRs were increased above those during the placebo period by $16 \%$. During BV therapy they had few symptoms, took hardly any bronchodilators and, in spite of this, their PEFRs were greater than during the placebo periods and $35 \%$ greater than during the SCG periods. Kuzemko et al. (1974), using lower daily doses $(400 \mu \mathrm{g} \mathrm{BV}$ and $40 \mathrm{mg}$ SCG) in children reasonably well controlled by SCG, found no difference in bronchodilator usage during the treatment periods in contrast to the marked reduction during BV in this trial. Frears and Friedman (1974) could not show any difference between $800 \mu \mathrm{g}$ and $400 \mu \mathrm{g}$ BV daily in their group of children.

In a study of eleven children, Hiller and Milner (1975) reported that the mean morning PEFR was lower during SCG therapy than during a corresponding placebo period, but they did not specify bronchodilator usage in these two periods. That reduction may be explained by having selected patients who were not satisfactorily controlled on SCG. Despite the different criteria of patient selection in those trials and the present one, all have indicated BV to be superior to SCG as a prophylactic treatment in childhood asthma.

At a dose of $800 \mu \mathrm{g} /$ day for 4 weeks BV did not seem to affect the children's response to tetracosactrin. This is in agreement with reports by Friedman and Frears (1974) and by Taylor and Norman (1974).

Candida albicans did not cause any clinical problems and rarely seems to do so in children receiving steroid aerosols (Frears and Friedman, 1974). No other adverse reactions were noted with either drug, so they seem similar in this respect.

Some difficulties may be encountered in very young children with either SCG or BV. Although the Spinhaler is an ingenious device for the administration of SCG powder when synchronized with good inspiratory flow rates, some parents may find BV easier to administer to a young child than to persuade the child to breathe in through the Spinhaler. The physician must find time to instruct the patient or parent properly in the use of the aerosols. It is important to demonstrate to patient and parent how and when to depress the aerosol canister, and to observe their efforts. A cloud of white powder coming through the child's mouth or nostrils strongly suggests bad synchronization. The purpose of this report is not to under-value the usefulness of SCG, since many children have gained benefit from this drug and are well controlled on it. However, if 
frequent bronchodilators are needed in addition to SCG, or if they require a SCG compound, which contains isoprenaline, it is suggested that BV should be tried as an alternative, without SCG, as Hiller and Milner (1975) were unable to demonstrate additional benefit of the combination over BV alone.

In conclusion, this short-term trial has shown that inhaled betamethasone valerate at a fixed dose (200 $\mu \mathrm{g}$ q.i.d.) is as well tolerated and as rapidly effective as sodium cromoglycate $(20 \mathrm{mg}$ q.i.d.) but that it provides a superior degree of control of asthma in children who are responding sub-optimally to bronchodilators.

\section{Acknowledgments}

We thank our patients for their co-operation and the staff of the hospitals for their help. We are grateful to Miss Lorraine Donovan for secretarial assistance, Mrs Anne $\mathrm{Ng}$ for data processing and Miss Andrea Chamberlain who arranged for the drugs to be suitably coded by Glaxo Laboratories Ltd.

\section{References}

Chai, H., Molk, L., Falliers, C.J. \& Miklich, D. (1970) In : Proceedings of the VII International Congress of Allergology, Vol. 232, p. 385. Excerpta Medica, Amsterdam.

Connolly, N. \& Godfrey, S. (1970) Assessment of a child with asthma Journal of Asthma Research, 8, 31.

Dickson, W., Hall, C.E., Ellis, M. \& Horrocks, R.H. (1973) Beclomethasone dipropionate aerosol in childhood asthma. Archives of Disease in Childhood, 48, 671.

FrEARS, J. \& Friedman, M. (1974) Experience in the use of betamethasone valerate by aerosol in asthmatic children. Postgraduate Medical Journal (Suppl. 4), 50, 50.

Frears, J.F., Wilson, L.C. \& Friedman, M. (1973) Betamethasone 17-valerate by aerosol in childhood asthma. Archives of Disease in Childhood, 48, 856.
Friedman, M. and Frears, J. (1974) Hypothalamic-pituitaryadrenal function and growth in asthmatic children on long term betamethasone valerate aerosol. Postgraduate Medical Journal (Suppl. 4), 50, 33.

Godfrey, S., Balfour-LynN, L. \& KöNig, P. (1975) Cromolyn sodium in long-term management of asthma. Journal of Pediatrics, 87, 465.

Hiller, E.J. \& Milner, A.D. (1975) Betamethasone 17 valerate aerosol and disodium cromoglycate in severe childhood asthma. British Journal of Diseases of the Chest, 69, 103.

Hills, E.A., Davies, S. \& Geary, M. (1974) The effect of betamethasone valerate aerosol in exercise-induced asthma. Postgraduate Medical Journal (Suppl. 4), 50, 67.

Hodgson, S.V., McPherson, A. \& Friedman, M. (1974) The effect of betamethasone valerate aerosol on exerciseinduced asthma in children. Postgraduate Medical Journal (Suppl. 4), 50, 69.

How.ARD, K. \& JACOBY, N.M. (1974) Betamethasone valerate treatment of steroid dependent children. Postgraduate Medical Journal (Suppl. 4), 50, 41.

KuZemKo, J.A., Bedford, S., Wilson, L. \& WAlker, S.R. (1974) A comparison of betamethasone valerate aerosol aud sodium cromoglycate in children with reversible airways obstruction. Postgraduate Medical Journal (Suppl. 4), 50, 53.

Polgar, G. \& Promadhat, V. (1971) In: Pulmonary Function Testing in Children: Techniques and Standards, p. 211. W. B. Saunders Company, Philadelphia, London, Toronto.

Silverman, M., Connolly, N., Balfour-Lynn, L. \& GODFREY, S. (1972) Long-term trial of disodium cromoglycate and isoprenaline in children with asthma. British Medical Journal, 3, 378.

Smith, J.M. \& Devey, G.F. (1968) Clinical trial of disodium cromoglycate in treatment of asthma in children. Britis Medical Journal, 2, 340.

TAYLOR, B. \& NORMAN, A.P. (1974) Betamethasone valerateaerosol in children not on previous steroid therapy. Postgraduate Medical Journal (Suppl. 4), 50, 44.

Wood, J.B., Frankland, A.W., James, V.H.T. \& Landon, J. (1965) A rapid test of adrenocortical function. Lancet, $i$, 243. 